\title{
A INCIDÊNCIA E A EFICÁCIA DA VACINA CONTRA O HPV EM HOMENS NA AMÉRICA DO SUL
}

Vitória Monteiro da Luz CAMARGO1*

Carla Marconi CORRÊA²

Tais Aparecida da SILVA ${ }^{3}$

RaizaAdrielle Ferraz Pacheco da SILVEIRA ${ }^{4}$

Luiz Henrique Ledesma PEREIRA ${ }^{5}$

Laura Ferreira de REZENDE ${ }^{6}$

\author{
${ }^{1-4}$ Discentes do Curso de Medicina UNIFAE \\ ${ }^{5}$ Médico Urologista e Docente do Curso de Medicina da UNIFAE \\ ${ }^{6}$ Mestre e Doutora pela Faculdade de Ciências Médicas UNICAMP e pós-doutora pela UNESP. laura@fae.br \\ *vitória.mcluz@gmail.com
}

Recebido em: 18/11/2016 - Aprovado em: 20/11/2017 - Disponibilizado em: 30/12/2017

\begin{abstract}
RESUMO
A avaliação do HPV em homens em relação a incidência e a aplicação de vacinas são assuntos recorrentes, pois a última administração em jovens evita de forma significativa a manifestação clínica das estirpes virais mais frequentes, sendo o HPV 6, 11, 16 e 18 e assim reduz as consequências dessa DST que podem muitas vezes ser assintomática e permitir a transmissão para homens e mulheres. Desenvolveu-se um estudo de revisão correlacionando a incidência do HPV em homens e a eficácia da vacina para esse gênero na América do Sul. A hipótese, embasada em artigos científicos relata que o vírus é o desencadeador de doenças como verrugas genitais, carcinoma de pênis, neoplasias de pênis e câncer anal e de orofaringe. Esse estudo foi embasado nas bases de dados Pubmed e Scielo, no qual foi levantado as idades, ocorrências de infecção e a aplicação da vacina como forma de prevenção.
\end{abstract}

Palavras chave: Papillomaviridae. Men. Vaccine. HPV. Incidence.

\section{ABSTRACT}

The evaluation of HPV in men in relation to the incidence and the application of vaccines are recurrent subjects, since the last administration in young people, significantly avoids the clinical manifestation of the most frequent viral strains, being HPV 6, 11, 16 and 18 and thus reduces the consequences of this STI, that can often be asymptomatic and allow transmission to men and women. A review study has been developed correlating the incidence of HPV in men and the efficacy of the vaccine to this gender in South America. The hypothesis, based on scientific articles reports that the virus is the trigger of diseases like genital warts, penile carcinoma, neoplasm of Penis and anal and oropharyngeal cancer. This study was based on the Pubmed and Scielo site databases, in which the ages, occurrences of infection and the application of the vaccine as a form of prevention were raised.

Keywords: Papillomaviridae. Men. Vaccine. HPV. Incidence.

\section{Introdução}

Nos últimos anos, o vírus HPV tornou-se de alta prevalência sendo os tipos mais frequentes 6, 16, 42 e 51 (FREIRE et al, 2014). O papilomavírus humano está ligado ao desenvolvimento do câncer de colo deútero, e é também um grande fator de risco para outros tipos de câncer. É uma doença transmitida sexualmente que pode desenvolver verrugas genitais, carcinoma de pênis, neoplasias intraperitoneais de pênis e câncer anal e de orofaringe (FREIRE E BLAS, 2014). Tem alta incidência em homens que se relacionam com homens (BLAS et al, 2014). Esse gênero é considerado um reservatório e um importante 
transmissor do vírus do HPV tanto para homens quanto para mulheres. (ALVAREZ et al, 2013; COSTUKER et al, 2014).

Como forma de prevenção existem dois tipos de vacina atualmente, a quadrilavente (HPV4) e a vacina contra o HPV oncogênico (HPV2). Ambas são compostas por partículas víruslike (VLPs) preparadas pela técnica de DNA recombinante. A vacina HPV4 contém VLPs semelhantes aos HPVs tipos 6, 11, 16 e 18 e a vacina HPV2 contém VLPs semelhantes aos HPVs tipos 16 e 18. A partir do estudo observou-se que a vacina é indicada para indivíduos de ambos os gêneros, com idade entre 9 e 26 anos. Ela deve ser administrada com intervalos de 0, 2 e 6 meses. (MELLO et al, 2013). Como essa é uma vacina inerte devido a sua produção, de forma não infectante, não há contraindicação para indivíduos imunodeprimidos.

Além de obterem uma resposta eficaz na prevenção de lesões cancerosas e condilomas genitais, os dois tipos de vacina, quadrivalente e bivalente, ficaram disponíveis em 2006 e 2008 respectivamente; mas apenas no setor privado no Brasil (OSIS et al, 2013). Assim, essa revisão sistemática tem como objetivo avaliar a incidência das doenças relacionadas ao vírus HPV e a eficiência da vacina contra o HPV aplicada em homens.

\section{Método}

Este estudo propõe fazer uma revisão sistemática relacionando a incidência de HPV em homens e a eficiência da vacina contra HPV para esse gênero na América do Sul. Foi utilizado as bases de dados Pubmed e Scielo, cruzando aleatoriamente as palavras chaves: PAPILLOMAVIRIDAE, MEN, VACCINE E HPV. Foram encontrados artigos em três diferentes idiomas, português, inglês e espanhol. Dessa maneira foram selecionados artigos datados a partir de 2012 que atendessem os objetivos propostos.

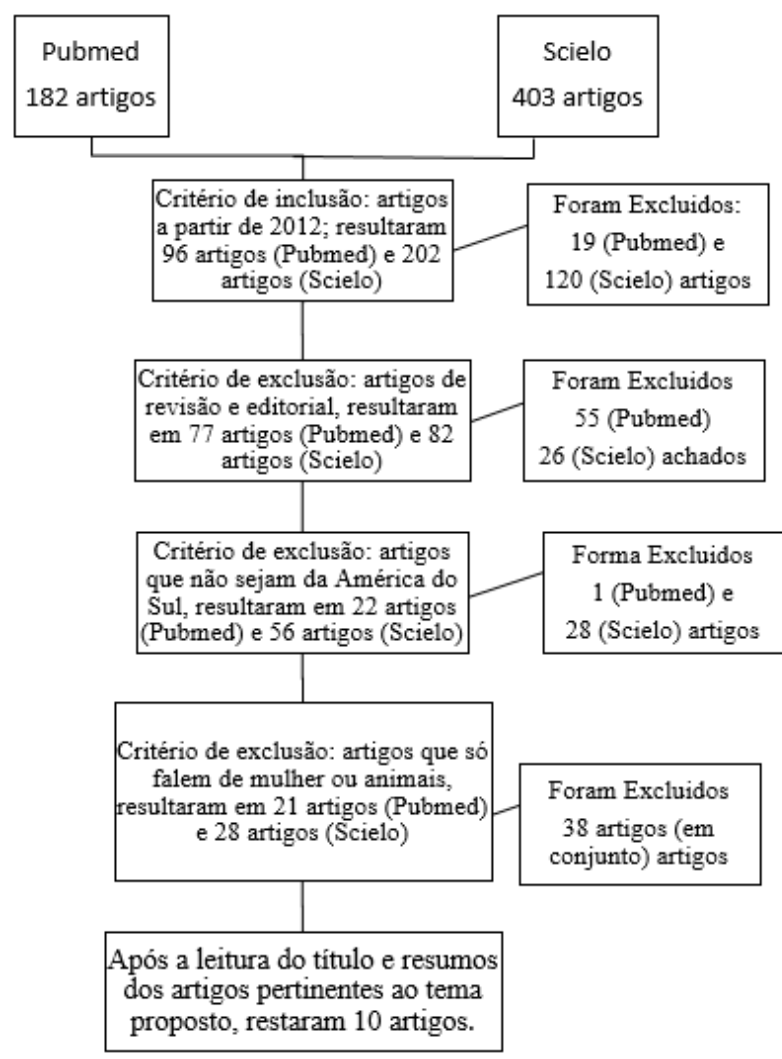

\section{Resultados}

Depois das buscas dos artigos nas bases de dados Pubmed e Scielo Brasil, restaram 10 
artigos para o estudo. A partir deles a tabela

abaixo foi elaborada: 
Tabela I - Descrição dos artigos selecionados nas b ases de dados PubMed, e Scielo, quanto aos autores, ao desenho de estudo, métodos, resultados e explicações para as inferências.

\begin{tabular}{|c|c|c|c|c|}
\hline Autor (Ano) & Método & Avaliação & Resultados & \\
\hline $\begin{array}{l}\text { Freire et al } \\
(2014)\end{array}$ & Coorte & $\begin{array}{l}366 \text { homens de março a outubro de } 2010 . \\
\text { Avaliação diagnóstica do HPV com base nos } \\
\text { Critérios: } \\
\text { 1. presença de uma verruga genital; } \\
\text { 2. presença de lesão genital atípica; } \\
\text { 3. ausência dos sintomas e um parceiro com } \\
\text { um diagnóstico de HPV; } \\
\text { 4. ausência de sintomas e um desejo de se } \\
\text { submeter a uma avaliação completa de } \\
\text { diagnóstico de DST*. }\end{array}$ & $\begin{array}{l}\text { - Dos } 366 \text { homens, } 11 \text { deram inconclusivos e } \\
\text { foram excluídos. } 256 \text { homens }(72,1 \% \text { dos } \\
\text { homens) obtiveram resutado positivo e } 99 \\
\text { testados negativos. } \\
\text { - O mais prevalente dos subtipos de HPV na } \\
\text { população estudada foram } 6,42,51 \text { e } 16 \text {. A } \\
\text { co-infecção foi encontrado em } 153 \text { homens. }\end{array}$ & $\begin{array}{l}\text { - A descrição genotipagem infecção por HPV é } \\
\text { uma importante ferramenta de diagnóstico. A } \\
\text { infecção por HPV em homens afeta grandemente } \\
\text { o risco de doença em mulheres. } \\
\text { - Oconhecimento da prevalência de HPV, seu } \\
\text { subtipo e distribuição etária podem orientar as } \\
\text { políticas de saúde pública e medidas de } \\
\text { prevenção, incluindo a vacinação. Esses dados } \\
\text { podem ser útil para monitorizar a prevalência de } \\
\text { HPV** tipos direcionados pela vacina após a } \\
\text { introdução. }\end{array}$ \\
\hline $\begin{array}{l}\text { Coskuner et } \\
\text { al (2014) }\end{array}$ & $\begin{array}{l}\text { Ensaio } \\
\text { clínico } \\
\text { randomizado } \\
\text { prospectivo }\end{array}$ & $\begin{array}{l}200 \text { homens com novas verrugas genitais } \\
100 \text { pacientes foram aleatoriamente } \\
\text { escolhidos para receber uma vacina } \\
\text { quadrivalente contra o HPV de intervenção } \\
\text { de três doses ao dia, entre } 2 \text { ou } 6 \text { meses. E } \\
100 \text { pacientes foram randomizados para o } \\
\text { grupo controle (não vacinados). } \\
\text { Os pacientes foram avaliados quanto idade, } \\
\text { estado civil, no de verrugas genitais visíveis } \\
\text { sob a lupa, o uso do preservativo, e } \\
\text { tabagismoem suas visitas iniciais e em cada } \\
\text { seguimento. }\end{array}$ & $\begin{array}{l}\text { - As verrugas genitais foram encontadas } \\
\text { principalmente no sulco coronal,eixo do } \\
\text { pénis, área púbica e perianal. } \\
\text { - A maioria das infecções por HPV são } \\
\text { transitórias e assintomáticas. Os homens têm } \\
\text { maior taxa de cura do que as mulheres. } \\
\text { - Infecção persistente com tipos de alto risco } \\
\text { pode evoluir para uma lesão pré-cancerosa. Os } \\
\text { HPV } 6 \text { e } 11 \text { são responsáveis por } 90 \% \text { das } \\
\text { verrugas genitais masculino e feminino. }\end{array}$ & $\begin{array}{l}\text { - O estado civil influenciou significativamente a } \\
\text { recorrência de verrugas. Homens casados tinham } \\
\text { mais recorências em nossa população. } \\
\text { - Os resultados do presente estudo também } \\
\text { mostraram que a vacina HVP não teve efeito } \\
\text { sobre a prevenção da recorrência. }\end{array}$ \\
\hline $\begin{array}{l}\text { Blas et al } \\
(2015)\end{array}$ & $\begin{array}{l}\text { Estudo } \\
\text { transversal }\end{array}$ & $\begin{array}{l}88 \text { perguntas sobre questões socias, } \\
\text { comportamentais (principalmente sexual), } \\
\text { doenças sexuais, sobre HPV, vacinação } \\
\text { contra o HPV e HPV-relacionadas ao cancer } \\
\text { e disposição para receber a vacina contra o } \\
\text { HPV. Foram estudados da seguinte maneira: } \\
\text { 1) uma lavagem oral para medir HPV na } \\
\text { cavidade oral, 2) inspeção de lesão genital } \\
\text { externa 3) coleta de amostras de } \\
\text { esfregaçodos glande, sulco coronal, eixo } \\
\text { pênis e escroto, 4) inspeção do perineal / } \\
\text { região perianal, 5) coleta de amostras de }\end{array}$ & $\begin{array}{l}\text { - A soroprevalência do genótipo HPV } \\
6 / 11 / 16 / 18 \text { ou tetravalente do HPV (HPV4) } \\
\text { entre HSH*** negativos e positivos foi de } \\
64,3 \% \text { e } 93,8 \% \text {. A positividade do HIV foi } \\
\text { associada a uma maior prevalência de HPV4 e } \\
\text { HPV 16/18 DNA nos locais genitais externos } \\
\text { e no canal anal. } \\
\text { - Embora muitos paises ofereçam a vacinação } \\
\text { contra o HPV às meninas, é necessária incluir } \\
\text { grupos com riscos de adquerir doença } \\
\text { associada ao HPV, como os HSH. }\end{array}$ & $\begin{array}{l}\text { - A razão proposta é a susceptibilidade da pele } \\
\text { anal e o trauma causado frequente durante o sexo } \\
\text { anal. } \\
\text { - Prevalência HPV maior em participantes com } \\
\text { HIV positivo pode ser devido a um aumento da } \\
\text { persistência de infecção por HPV, devido a baixa } \\
\text { imunidade ou a uma elevada incidência de novas } \\
\text { infecções, como consequência do comportamento } \\
\text { sexual. }\end{array}$ \\
\hline
\end{tabular}




\begin{tabular}{|c|c|c|c|c|}
\hline & & $\begin{array}{l}\text { esfregaço do canal anal 6) Papanicolaou anal } \\
\text { 7) coleção de swabs anais 8) teste para HPV } \\
\text { e teste de anticorpos. }\end{array}$ & & \\
\hline $\begin{array}{l}\text { Klinglmair } \\
\text { et al (2012) }\end{array}$ & $\begin{array}{l}\text { Coorte } \\
\text { prospectivo }\end{array}$ & $\begin{array}{l}250 \text { meninos e homens. } \\
\text { As amostras foram subdivididas em } 3 \text {, a } \\
\text { partir da idade, constituídos por } 125(50 \%) \\
\text { crianças }(0-10 \text { anos), } 38 \quad(15,2 \%) \\
\text { adolescentes }(11-20 \text { anos) e } 87(34,8 \%) \\
\text { adultos ([20 anos]. A hibridização in situ } \\
\text { (ISH) foi realizada para detectar tipos de } \\
\text { vírus HR }{ }^{1} \text { e LR }{ }^{2} \text { dentro do epitélio, seguido } \\
\text { de interpretação microscópica e } \\
\text { determinação entre padrão de sinal. }\end{array}$ & $\begin{array}{l}\text { Nossos resultados revelaram altos níveis de } \\
\text { concentração de HPV em todos os grupos } \\
\text { etários: HR }{ }^{1} \text { versus } \text { LR }^{2} \text { positividade foi } \\
\text { observado } 35 \% \quad \text { (crianças), } 63,6 \% \\
\text { (adolescentes) e } 48,6 \% \text { (adultos). A taxa mais } \\
\text { alta de HR }(59,8 \% \text { ) - e LR(50,6\%) - sondas } \\
\text { positivas foram encontradas no grupo com alta } \\
\text { atividade sexual estimada. }\end{array}$ & $\begin{array}{l}\text { - Quanto à alta prevalência da infecção de HPV } \\
\text { masculino, mesmo em crianças, indicou } \\
\text { transmissão não-sexual. Inclusão de meninos na } \\
\text { vacinaçãoparece ser necessário para reduzir a sua } \\
\text { carga de doenças relacionadas com o HPV. }\end{array}$ \\
\hline $\begin{array}{l}\text { Quintero et } \\
\text { AL } 2013\end{array}$ & $\begin{array}{l}\text { Estudo } \\
\text { transversal e } \\
\text { retrospectivo }\end{array}$ & $\begin{array}{l}\text { Cortes histológicos. Análise estatística da } \\
\text { detecção do DNA do HPV } \\
\text { - } 175 \text { casos incluídos } \\
\text { - A idade média do diagnóstico foi de } 64,5 \\
\text { anos. A maioria dos casos tinha entre } 50 \text { e } \\
70 \text { anos e eram do sexo masculino. }\end{array}$ & $\begin{array}{l}\text {-A prevalência do HPV foi de } 18,9 \% \text { entre } \\
1999 \text { e } 2008 \text {. } \\
\text { HPV foi encontrado em } 23,9 \%, 17,5 \% \text { e } \\
13,3 \% \text { dos casos de cavidade oral, laringe e } \\
\text { orofaringe respectivamente. } \\
\text { - } 27 \text { amostras eram positivas para HPV } 16 \text { e } 6 \\
\text { para HPV } 18\end{array}$ & $\begin{array}{l}\text {-A vacinação profilática para HPV tem } \\
\text { demonstrado eficácia. Os estudos demonstram } \\
\text { prevalência da vacina contra o HPV. } \\
\text { - A vacinação em massa contra o HPV poderá } \\
\text { possivelmente reduzir o número de casos de } \\
\text { câncer de cabeça e pescoço. }\end{array}$ \\
\hline $\begin{array}{ll}\text { Mello } & \text { et } \\
\operatorname{al}(2013)\end{array}$ & $\begin{array}{l}\text { Estudo } \\
\text { prospectivo } \\
\text { randomizado } \\
\text { duplo-cego }\end{array}$ & $\begin{array}{l}\text { Vacinação. Atualmente, temos dois tipos de } \\
\text { vacinas contra HPV: a quadrilavente } \\
\text { (HPV4) e a vacina contra o HPV oncogênico } \\
\text { (HPV2). Ela deve ser administrada com } \\
\text { esquemas de intervalos de } 0,2 \text { e } 6 \text { meses. }\end{array}$ & $\begin{array}{l}\text { Nesse estudo, demonstrou-se a efetividade em } \\
\text { prevenir a infecção pelo HPV tipos } 6,11,16 \text { e } \\
18 \text {, além da prevenção das lesões genitais } \\
\text { externas associadas a esses tipos de HPV nos } \\
\text { indivíduos que receberam a vacina HPV. }\end{array}$ & $\begin{array}{l}\text { A vacina contra o HPV constitui-se uma } \\
\text { importante ferramenta para prevenção da infecção } \\
\text { pelo HPV e doenças associadas. }\end{array}$ \\
\hline $\begin{array}{l}\text { Álvarez- } \\
\text { Argüelles et } \\
\text { al (2013) }\end{array}$ & $\begin{array}{l}\text { Estudo } \\
\text { Longitudinal }\end{array}$ & Fragmento de gene L1 e genes E6 e E7. & $\begin{array}{l}\text { Não houve nenhuma evidência entre idade e } \\
\text { infecção pelo HPV. } \\
\text { A maior frequiência do vírus de HPV foi dos } \\
\text { tipos } 6 \text { e } 11 \text {. } \\
\text { A vacina tetravalente é mais eficaz do que a } \\
\text { vacina bivalente na redução de condiloma } \\
\text { anal. }\end{array}$ & $\begin{array}{l}\text { A prevalência de HPV em homens era alta e } \\
\text { diminuiu com a idade.. A inclusão dos homens no } \\
\text { programa nacional de vacinação contra o HPV } \\
\text { pode reduzir sua carga de HPV- } \\
\text { relacionadosdoença e reduzir a transmissão do } \\
\text { vírus de mulheres não-vacinados. }\end{array}$ \\
\hline
\end{tabular}




\begin{tabular}{|c|c|c|c|c|}
\hline $\begin{array}{ll}\text { Swedish } & \text { et } \\
\text { al }(2014) & \end{array}$ & Coorte & $\begin{array}{l}210 \text { pacientes sem história de condiloma } \\
\text { anal e } 103 \text { pacientes previamente tratados } \\
\text { com condiloma anal. } \\
\text { Foi determinado a taxa de condiloma anal } \\
\text { entre pacientes vacianados e não vacinados. }\end{array}$ & $\begin{array}{l}313 \text { pacientes com idade média de } 42 \text { anos } \\
\text { foram acompanhados em média por } 981 \text { dias. } \\
\text { Durante } 773.6 \text { pessoas-anos de seguimento, } \\
\text { desenvolveram condiloma. Razão de risco } \\
\text { múltipla mostrou que estava associada com } \\
\text { qHPV a diminuição do risco de } \\
\text { desenvolvimento de condiloma anal. História } \\
\text { de condiloma anal era associada com risco } \\
\text { aumentado de desenvolvimento de condiloma } \\
\text { anal como foi a infecção com HPV } \\
\text { oncogênico. }\end{array}$ & $\begin{array}{l}\text { Este é o primeiro estudo a mostrar que qHPV **** } \\
\text { diminui o risco de condiloma anal entre HSH } \\
\text { mais velhos. Embora a vacina está atualmente } \\
\text { licenciada e recomendada para a prevenção da } \\
\text { infecção por HPV em Jovens com idades entre } 9 \text { a } \\
26 \text { anos, se os resultados forem confirmados por } \\
\text { umrandomizado, controlado por placebo, a idade } \\
\text { do alvo população deve ser expandido, } \\
\text { especialmente em populações de alto risco como } \\
\text { HSH. }\end{array}$ \\
\hline $\begin{array}{l}\text { Zou et al } \\
(2013)\end{array}$ & $\begin{array}{l}\text { Estudo } \\
\text { Transversal }\end{array}$ & $\begin{array}{l}200 \text { homens entre outubro de } 2010 \text { e } \\
\text { setembro de 2012. Os homens foram } \\
\text { testados para DNA do HPV a partir do ânus } \\
\text { e pênis e preencheram um questionário sobre } \\
\text { suas experiências sexuais. }\end{array}$ & $\begin{array}{l}\text { A proporção de homens com HPV anal de } \\
\text { qualquer tipo teve aumento de } 10,0 \% \text {. A } \\
\text { proporção de homens com HPV peniano } \\
\text { aumentou de } 3,7 \% \text { em homens que relataram } \\
\text { sexo anal. } \\
\text { Dos homens estudados tinham pelo menos um } \\
\text { tipo de HPV: tipos evitáveis por vacinação ( } 6 \text {, } \\
11,16 \text { ou 18). }\end{array}$ & $\begin{array}{l}\text { A transmissão de HPV foi precoce e alta. } \\
\text { A vacinação contra o HPV terá de começar cedo } \\
\text { para a prevenção máxima de HPV entre os HSH. }\end{array}$ \\
\hline $\begin{array}{l}\text { Goldstone et } \\
\text { al (2013) }\end{array}$ & $\begin{array}{l}\text { Ensaio } \\
\text { Clínico }\end{array}$ & $\begin{array}{l}364 \text { homens heterossexuais com idade entre } \\
16-24 \text { anos. } \\
602 \text { homens que fazem sexo com homens } \\
\text { com idade entre } 16-27 \text { anos e com menos de } \\
\text { seis parceiros sexuais ao longo da vida. } \\
\text { O objetivo era demonstrar que, comparado } \\
\text { com o placebo, a vacina contra HPV reduziu } \\
\text { a incidência de HPV 6, } 11,16 \text { ou } 18 . \\
\text { Homens com uma história de lesões genitais } \\
\text { clinicamente detectáveis relacionadas ao } \\
\text { HPV ou outras infecções sexualmente } \\
\text { transmissíveis foram excluídas. }\end{array}$ & $\begin{array}{l}\text { A idade média dos participantes foi de } 20,5 \\
\text { anos e a maioria dos participantes foi não } \\
\text { circuncisada }(61,9 \%) \text { e branca }(35,2 \%) \text {.A } \\
\text { eficácia estatisticamente significativa foi } \\
\text { alcançada contra lesões, grupo HPV } \\
6 / 11 / 16 / 18 \text { mas não houve eficácia } \\
\text { estatisticamente significativa para o } \\
\text { condiloma intra-anal relacionado a qualquer } \\
\text { HPV 6/11/16/18 ou independentemente da } \\
\text { detecção de HPV. }\end{array}$ & $\begin{array}{l}\text { Este relatório examina a eficácia contra a doença } \\
\text { causada por } 10 \text { tipos adicionais de HPV não } \\
\text { vacinados, bem como eficácia independentemente } \\
\text { de se ou não o HPV foi detectado em uma lesão.A } \\
\text { maior queda na eficácia no local intra-analpode } \\
\text { ser devido ao fato de que uma proporção maior de } \\
\text { doença anal é causada pelos } 10 \text { tipos de HPV } \\
\text { adicionais considerados.Em face de pouca ou } \\
\text { nenhuma proteção cruzada, isto diminuirá a } \\
\text { eficácia observada no local intra-anal. }\end{array}$ \\
\hline
\end{tabular}

${ }^{1}$ high-risk (HR): Alto risco

${ }^{2}$ low-risk (LR): baixo risco

*DST : Doença Sexualmente Transmissível

**HPV: Vírus Papiloma Humano

*** HSH: Homens que tem relação sexual com outros homens

**** qHPV: Vacina quadrivalente contra o HPV

Fonte: tabela elaborada pelo próprio autor com embasamento nos dados fornecidos pelos artigos científicos.

469

Revista da Universidade Vale do Rio Verde, Três Corações, v. 15, n. 2, p. 464-472, ago./dez. 2017 


\section{Discussão}

$\mathrm{O}$ vírus HPV pode ser dividido em mucosotrópicos, os quais infectam mucosas podendo causar condilomas (verrugas genitais), comumente associados aos tipos 6, 11 e 42, e em cutaneotrópicos que estão associados a infecções da epiderme, onde podem causar verrugas (tipo 1 e 2) e até mesmo câncer de pele (tipo 5 e 8). Os vírus classificados como mucosotrópicos de alto risco (16 e 18) são os associados ao desenvolvimento de mais de $90 \%$ dos casos de câncer de ânus, pênis, pele, orofaringe e à papilomatose respiratória recorrente, um tumor benigno que acomete a laringe, podendo afetar todo o trato respiratório (NIQUIRILO et al, 2016).

A incidência de HPV em homens é alta e em um estudo realizado com 256 homens positivos para a infecção do HPV foram divididos em grupos por idade, sendo meiaidade (50-59 anos) com 78,8\%, adultos jovens (30-39 anos) com 76,9\% e jovens (18-29 anos) com 76,7\% (FREIRE et al, 2014). Relacionada a faixa etária não há consenso. Observou-se uma dicotomia, na qual existe alta prevalência entre jovens (ÁLVAREZ-ARGÜELLES et al, 2013) e em homens de mais idade, com média de diagnóstico entre 64,5 anos (QUINTERO et al, 2013).

Os tipos maléficos mais frequentes do vírus HPV são 6, 11, 16 e 18 (FREIRE et al,
2014; COSKUNER et al, 2014). Portanto as vacinas produzidas cobrem principalmente esses vírus, como a vacina HPV4 que contém partícula viral inativa semelhantes aos HPVs tipos 6, 11, 16 e 18 e a vacina HPV2 que contém partícula viral inativa semelhantes aos HPVs tipos 16 e 18.

Antes de ser implantada ao calendário de vacinação do Brasil, um estudo na população brasileira a respeito da vacina deixou claro a falta de informação sobre a sua importância e o modo de acesso a mesma (NIQUIRILO et al, 2016).

No estudo da vacina Gardasil ${ }^{\circledR}$ em jovens e homens, observou-se 3 casos de lesões genitais em 1400 indivíduos que receberam as vacinas, e 32 casos dos que receberam o placebo. Em relação às lesões anais précancerosas, observaram-se 5 casos no grupo que recebeu a vacina em 200 jovens e homens, e 24 casos no grupo do placebo em 200 indivíduos. Prevê-se também que a proteção contra as lesões pré-cancerosas se traduza em proteção contra o câncer (NIQUIRILO et al, 2016).

A infecção prévia pelo HPV não constitui uma contraindicação para a vacinação (MELLO et al, 2013). Como é uma vacina de vírus inerte, não há contraindicação para indivíduos imunodeprimidos. As duas vacinas para o HPV possuem boa tolerabilidade, com baixa ocorrência de 
eventos adversos, sendo os mais comuns dor e edema no local da aplicação.

\section{Conclusão}

O levantamento dos estudos mostrou a alta incidência da infecção do vírus HPV em homens e também que a vacina contra o HPV é uma importante ferramenta que se provou eficaz para prevenção da infecção pelo HPV e para as doenças associadas,

\section{Referências}

ÁLVAREZ-ARGUELLES, M. E. et al. Human Papillomavirus Infection in a Male Population Attending a Sexually Transmitted Infection Service. PLOS ONE, Portugal, v. 8, n.1, January 23, 2013.

BLAS, M. M. et al. HPV Prevalence in Multiple Anatomical Sites among Men Who Have Sex with Men in Peru. PLOS ONE, Maringá, v. 209, p. 642-5, 2014.

COSTUKER, E. R. et al. Impact of the Quadrivalent HPV Vaccine on Disease Recurrence in Men Exposed to HPV Infection: A Randomized Study.

InternationalSociety for Sexual Medicine, v.11, p.2785-2791, 2014.

FREIRE, M. P. et al. Genital prevalence of HPV types and co-infection in men. IBJU Genital prevalence of HPV, Sao Paulo, v. 40, n.1, p. 67-71, Jan/Feb 2014.

GOLDSTONEA, S. E. et al. Quadrivalent HPV vaccine efficacy against disease related to vaccineand non-vaccine HPV types in males. Vaccine, v. 31, p. 3849- 3855, 2013.

KLINGLMAIR, G. et al. Prevalence of the human papillomavirus (HPV) expression of the inner prepuce in asymptomatic boys and principalmente se aplicada em jovens. É importante salientar que a vacinação do sexo masculino diminui concomitantemente a transmissão do vírus para as mulheres e assim reduz as lesões causadas em ambos os gêneros, diminuindo os gastos públicos com diagnósticos e tratamento dos agravos. Portanto, é fundamental a inclusão da vacina contra o HPV para homens na caderneta de vacinação nacional.

men.World J Urol, v.31, p. 1389-1394, 2013.

MELLO, et al. Vacinação contra papilomavírus humano. Einstein; v.11, n. 4, p. 547-549, 2013.

NIQUIRILO A. T. et al. Eficácia e segurança da vacinação contra o Papiloma Vírus Humano no programa nacional de imunização. Atas de Ciências da Saúde, São Paulo, v. 4, n. 1, p. 01-11, 2016.

OSIS M. J. D. et al. Conhecimento e atitude de usuários do SUS sobre o HPV e as vacinas disponíveis no Brasil. Rev Saúde Pública, v. 48, n. 1, p. 123-133, 2014.

QUINTERO, K. et al. Human papillomavirus types in cases of squamous cell carcinoma of head and neck in Colombia. Brazilian Journal of orhinolaryngology, v.79, n.3, p.375-81, mai/jun, 2013.

SANTOS I. M. et al. Infecção por HPV em homens: Importância na transmissão, tratamento e prevenção do vírus. EstudBiol, v. 32/33, n. 76-81, p. 111-18, 2011

SWEDISH, K. A. et al. Prevention of Anal Condyloma with Quadrivalent Human Papillomavirus Vaccination of Older Men 
Who Have Sex with Men. PlosOne,

Maringá, n.4, v.9, e93393, 2014.

ZOU, H. et al. Early Acquisition of

Anogenital Human Papillomavirus Among

Teenage Men Who Have SexWith Men.

The Journal of Infectious Diseases, v. 209, p.642-51, 2014. 